\title{
Treating Open Fracture of Lower One Third of Tibia by Ilizarov Technique: A Study in a Tertiary Care Hospital of Bangladesh
}

\author{
Erfanul Huq Siddiqui ${ }^{1,}$, , Sheikh Forhad ${ }^{1}$, Md Shamsul Alam ${ }^{2}$, Jannat Sultana $^{3}$, MAA Shameem ${ }^{4}$ \\ ${ }^{1}$ Department of Orthopaedic Surgery, Bangabandhu Sheikh Mujib Medical University (BSMMU), Dhaka, Bangladesh \\ ${ }^{2}$ Department of Orthopedics, Gazaria Upazila Health Complex, Munshigonj, Bangladesh \\ ${ }^{3}$ Department Paediatric Medicine, Bangabandhu Sheikh Mujib Medical University (BSMMU), Dhaka, Bangladesh \\ ${ }^{4}$ Department of Orthopedics, Border Guard Hospital, Pilkhana, Dhaka, Bangladesh
}

\section{Email address:}

drerfanulhuq@gmail.com (E. H. Siddiqui)

${ }^{*}$ Corresponding author

\section{To cite this article:}

Erfanul Huq Siddiqui, Sheikh Forhad, Md Shamsul Alam, Jannat Sultana, MAA Shameem. Treating Open Fracture of Lower One Third of Tibia by Ilizarov Technique: A Study in a Tertiary Care Hospital of Bangladesh. American Journal of Biomedical and Life Sciences. Vol. 9, No. 2, 2021, pp. 128-132. doi: 10.11648/j.ajbls.20210902.14

Received: March 20, 2021; Accepted: April 2, 2021; Published: April 30, 2021

\begin{abstract}
Introduction: Illizarov technique is a newer but popular method of treating open tibial fractures after debridement and open reduction. Illizarov method has many advantages and features. On the other hand, open fracture of lower one third of tibia is a common occurrence in the orthopedic treatment arena. Open fractures of tibia are classified into Type I, II, IIIA, IIIB and IIIC. Aim of the study: The aim of this study was to assess the Ilizarov technique in treating open fracture of lower one third of tibia. Methods: This observational prospective study was conducted at the Department of Orthopedics Surgery in Bangabandhu Sheikh Mujib Medical University (BSMMU), Dhaka, Bangladesh during the period from January 2017 to December 2017. Thirty six (36) patients with open fracture of lower one third of tibia were selected as the study population. Before starting the intervention the written consent of the participants was taken and this study was approved by the ethical committee of the mentioned hospital. A pre-designed questioner was used in collecting patient data. All data were processed, analyzed and disseminated by MS Office and SPSS version 20 as per need. Results: In this study we found highest $80.56 \%$ participants were from road accidents followed by $11.11 \%$ from sports injury and rest only $8.33 \%$ from general falls. The duration of treatment with the fixator was 12-23 weeks (average 16 weeks). The operation time ranged from 90 minutes to 120 minutes. According to the Karlstrom and Olerud criteria the highest $69.44 \%$ patient got 'excellent' result. Then $22.22 \%, 5.56 \%$ and $2.78 \%$ patients got 'good', 'fair' and 'poor' result respectively. Conclusion: The Ilizarov device is used worldwide for the treatment of several types of fractures. In our study, we found some good features of using Ilizarov induced method in the treatment of open fracture of lower one third of tibia. No case developed deep infection, non-union or unacceptable mal-union. We recommend for more use of Ilizarov technic.
\end{abstract}

Keywords: Open fractures, Illizarov, Fixator, Tibia, Proximal, Distal

\section{Introduction}

Illizarov technique is a newer but popular method of treating open tibial fractures after debridement and open reduction. Illizarov method has many advantages and features. On the other hand, open fracture of tibia is a common occurrence in the orthopedic treatment arena. Open fractures of tibia are classified into Type I, II, IIIA, IIIB and IIIC. Tibial fractures are the most common long bone fractures, with around $25 \%$ being open fractures.[1] The majority of open tibial fractures result from high velocity trauma such as road traffic accidents and falls from height. The management of these fractures can be complex due to the relative lack of soft tissue coverage and blood supply of the tibial shaft.[2] Prognosis depends on the amount of initial 
bone displacement, comminution, and soft tissue injury. Advanced bone reconstruction and soft tissue coverage is usually required to achieve bone and soft tissue healing.[3] Thus, the rate of complications associated with open tibial fractures is high; infection, non-union and limb loss are the major causes of morbidity[4] Selection of any of all the methods are related with surgeon's decision and economic status of the patients. In North America, most of surgeons do reamed nailing for the treatment of open or closed tibial fractures. In developing countries because of low facilities and lack of medical instruments, the selection of each method may differ.[5] Recently, external fixators like Ilizarov or AO external fixator are used extensively in developing countries but the rates of mal-union and infection are relatively high.[6] With AO external fixator, the efficacy of treatment in two studies were reported to be $20-31 \%$. [7] Open fractures are classified into three major categories, depending on the mechanism of injury, soft tissue damage, and degree of skeletal involvement.[8] Type I open fracture is characterized by a puncture wound around $1 \mathrm{~cm}$ or less in diameter and is relatively clean in condition. Type II open fracture has laceration more than $1 \mathrm{~cm}$ long and less than $10 \mathrm{~cm}$, without extensive soft tissue, flaps, or avulsion, with a minimal to moderate crushing component. The fracture is usually with minimal comminution. Besides these, type III open fracture is one that involves extensive damage to the soft tissue, including muscles, skin and neurovascular structures. The type III open fractures are further divided into three subtypes. Type IIIA indicates open fracture with adequate soft tissue coverage of a fractured bone despite extensive soft tissue laceration or flaps, or high-energy trauma (gunshot and farm injuries) regardless of the size of the wound. [9] Type IIIB indicates open fracture with extensive soft-tissue loss and periosteal stripping and bone damage. Usually associated with massive contamination [10] which will often need further soft-tissue coverage procedure. On the other hand, Type IIIC indicates open fracture associated with an arterial injury requiring repair, irrespective of degree of soft-tissue injury. Different methods for the treatment of open fracture shaft tibia (after debridement \& open reduction) include POP cast immobilization, external fixation, open reduction and plating, locked intramedullary nailing. According to Trafton, [11] complications include deep infection, acute or chronic osteitis or ostiomyelitis, delayed union, non-union, mal- union, loss of alignment in cast or brace, fixation problems. Gavril A Ilizarov, a Russian physician, devised this method of treatment of open fractures of tibia. The Ilizarov ring supports transfixional K-wire or haft pins, which can be fixed at the many holes site on the 360-degree ring. It has two or more connected rings that form a frame of the apparatus. The rings bear supplementary part of the frame necessary for dynamic bone treatment. [12] They are basically elastic type of external fixator and allow axial micro-motion that is conductive to healing of fractures and regenerate. Forces acting in the circular fixator are in a plane. It is a multilevel and multi-planner fixator. The circumferential rings of ilizarov distribute stresses more evenly across the fracture or osteotomy sites. Therefore, three dimensional corrections become possible. Axial distraction or compression angular and translational corrections are all possible using gradual mechanical techniques. On the other hand, circular fixator is a stable and elastic fixator. These types of fixators allow immediate weight bearing and function. As the wires are thin, the holes are small. Circular fixators can have capacity for three dimensional corrections. The Ilizarov devices are able to control shear at the fracture site while allowing axial and bending flexibilities producing an ideal environment for bone healing. Wire stoppers add shear rigidity to the system. Circular fixators are better for patients with osteoporosis using wire. The aim of this study was to assess the Ilizarov technique in treating open fracture of lower one third of tibia.

\section{Objectives}

General objective:

To assess the Ilizarov technique in treating open fracture of lower one third of tibia.

Specific Objectives:

To evaluate the fracture patterns of fractures.

To evaluate the types and locations of fractures.

\section{Methodology \& Materials}

This was an observational prospective study. The study was conducted at the Department of Orthopedics Surgery in Bangabandhu Sheikh Mujib Medical University (BSMMU), Dhaka, Bangladesh during the period from January 2017 to December 2017. In total 36 patients with open fracture of lower one third of tibia were selected as the study population. Before starting the intervention the written consent of the participants was taken and this study was approved by the ethical committee of the mentioned hospital. According to the exclusion criteria patients with closed fracture, pathological fractures and type IIIC fractures were rejected from this study. The fractures were assessed by AP and Lateral X-ray. Fractures were classified according to Gustilo's fracture classification of open fractures. Patients with compound tibial fractures were taken to the operating room for debridement as soon as possible. These fractures were managed provisionally in long leg posterior slab or long leg posterior cast with a window for dressing changes. Necessary fluids and electrolytes replacement or whole blood transfusion were given as per requirement of each patient. Definitive treatment of fracture was done as routine case usually in a week. Patients were operated under general or spinal anaesthesia as per need. Pre-assembly of the frame was done one day prior to surgery. Distance between the rings was adjusted according to the fracture anatomy. Fracture with minimal comminution and length loss less than $1 \mathrm{~cm}$ was usually managed with a four ring frame, more complex fracture needed more number of rings. Wires were fixed to the rings with ring fixator bolt after tensioning up to 90-110 kg using a dynamometer. The rings were kept 2 finger 
breadths from skin all around. Reduction was checked with $\mathrm{C}$-arm image intensifier on the table and adjustments done according at the same setting. The pin tract wounds were dressed by povidone iodine solution $(10 \%)$ and covered with pad. Pin site was cleaned everyday with spirit or povidone iodine (10\% solution). When clot and crust was present, weak solution of hydrogen peroxide $\left(\mathrm{H}_{2} \mathrm{O}_{2}\right)$ was applied to remove it. When pin tract wound was inflamed or discharge was present, oral antibiotics were given. Partial weight bearing with axillary crutch was allowed as soon as the patient could tolerate the pain. The frame and wire was checked whenever the patients complained of pain, stability. Tension of the wire was checked and retensioning was done as per need. Check X-ray was taken on first or second postoperative day and reduction was checked. Equinus deformity was prevented by active and passive movement of ankle. If ankle movement was painful, foot was supported with a slipper or boot cast tied to the last ring. The patients were followed up at an interval of 2 weeks for a minimum period of 8 weeks, thereafter every month for 3 months and subsequently 3 monthly till a period of 1 year. Checkradiographs were taken on the next day and then at 6th week, 12 th week and 36th week. The patients were assessed clinically for the range of movement of the knee and ankle respectively, pain at the fracture site, anterior knee pain, ankle joint symptoms, infection, muscular atrophy, clinical union, difficulty in walking and performing daily routine. Frames were removed after clinico-radiological union. The fracture was regarded to be united (1) if the patient could walk without support after loosening the frame crossing the fracture site and not tender at fracture site (2) if there was no mobility at fracture site after loosening the frame and (3) radiologically, if there was enough callus across the fracture site and obliteration of the fracture line. The frame was removed at the outpatients department or in the operation theatre once the fracture was united. If the frame was removed before the union of fracture due to infection or frame intolerance patellar tendon bearing POP cast was applied. At the end of follow-up period, the results were grouped into excellent, good, fair and poor using modified criteria of Karlstrom and Olerud.

\section{Results}

In our study among total 36 participants $69 \%(n=25)$ were male and $31 \%(n=11)$ were female. So male was dominating in number. In age distribution we found $38.89 \%$ form $18-30$ years' age group which was the highest number. This ratio was followed by $36.11 \%$ from $31-40$ years' age group, $13.89 \%$ from 41-50 years' age group, 8.33\% from 51-60 years' age group and rest $2.78 \%$ from $>60$ years' age group. According to collected data the highest $56 \%$ participants were with type II open fracture followed by $33 \%$ with type I open fracture and rest $11 \%$ with type III A open fracture. On the other hand, among total 36 participants the highest $64 \%$ patients had middle location fractures followed by $22 \%$ had proximal location and rest $14 \%$ had distal location fracture. In analyzing the patterns of open fractures we found highest $52.78 \%$ patients had comminuted fracture followed by $19.44 \%$ had transverse, $13.89 \%$ had oblique, $8.33 \%$ had spiral and rest $5.56 \%$ had segmental open fractures. Among total study population the highest $64 \%$ patients had right side open fracture whereas $36 \%$ had left side open fractures. In analyzing the mode of injuries we found the highest $80.56 \%$ participants were from road traffic accidents (RTA) followed by $11.11 \%$ from sports injury and rest only $8.33 \%$ from general falls (falls from height). The duration of treatment with the fixator was 12-23 weeks (average 16 weeks). Nineteen patients wore a PTB cast for an additional period of 4 weeks. In our study total 36 cases were debrided on the same day and stabilized with Ilizarov ring faxator after a period of 5 to 12 days from the date of injury. The operation time ranged from 90 minutes to 120 minutes (Mean $102 \pm 6.5$ minutes). The Ilizarov external fixator was withdrawn when there was clinico-radiological union. The duration of treatment with the fixator ranged from 12 to 22 weeks (Mean $16 \pm 3$ weeks). The time to union varied from 21 to 28 weeks (average 24.50 weeks). The average time of union was 21 weeks for Type I open fractures, 22.5 weeks for Type II open fractures and 27 weeks for Type IIIA open fractures. The complications of compound fracture of tibia with Ilizarov ring fixator were broadly divided into intra-operative, postoperative and delayed complications. There was no intraoperative complication. As for the postoperative complications, local pain with motion and local oedema were seen in 4 cases $(11.11 \%)$ and painful tenting of skin in 7 cases $(19.44 \%)$. Delayed complications included pin tract infection in $22.22 \%$ patients, loss of 80 ankle dorisflexion in 3 cases, shortening of $1 \mathrm{~cm}$ was seen in 2 case $(5.5 \%), 2$ cases $(5.5 \%)$ of united in 70 recurvatum as calculated radiologically, 2 cases $(5.5 \%)$ of muscle wasting of the leg from 0.4 to $1.5 \mathrm{~cm}$. No case developed deep infection, nonunion or unacceptable malunion. Only one patient got 2 weeks more treatment than all the others patients. Finally in analyzing the outcomes of this technic according to the Karlstrom and Olerud criteria the highest $69.44 \%$ patient got 'excellent' result. Then $22.22 \%, 5.56 \%$ and $2.78 \%$ patients got 'good', 'fair' and 'poor' result respectively.

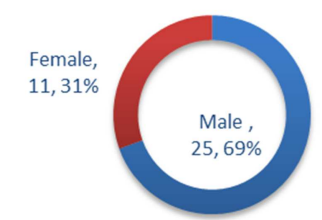

Figure 1. Gender distribution of participants $(n=36)$.

Table 1. Age distribution of participants $(N=36)$.

\begin{tabular}{lll}
\hline Age (Yrs.) & n & \% \\
\hline $18-30$ & 14 & 38.89 \\
$31-40$ & 13 & 36.11 \\
$41-50$ & 5 & 13.89 \\
$51-60$ & 3 & 8.33 \\
$>60$ & 1 & 2.78 \\
\hline
\end{tabular}




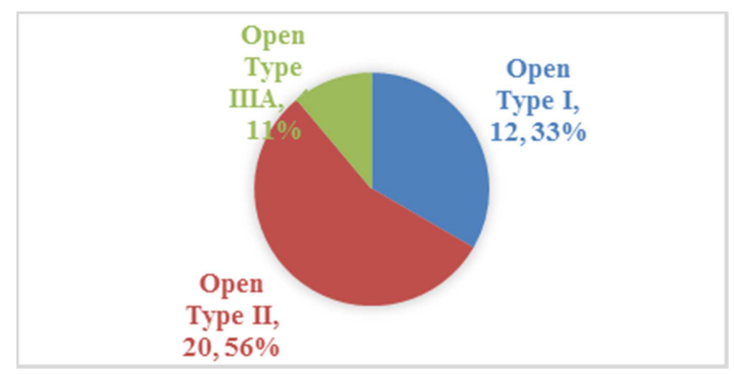

Figure 2. Distribution of types of fractures $(n=36)$.

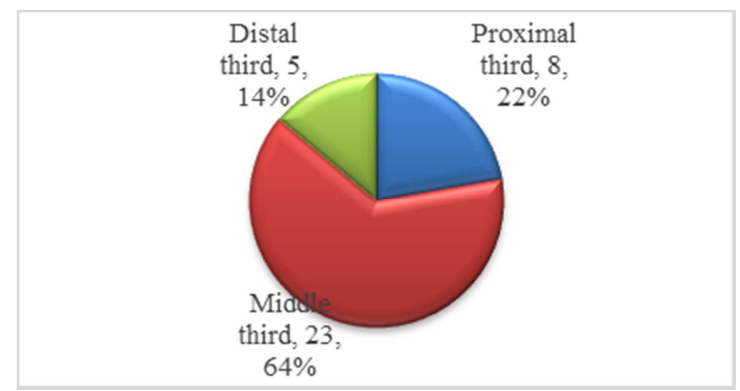

Figure 3. Distribution of locations of fractures $(n=36)$.

Table 2. Distribution of patterns of fractures $(n=36)$.

\begin{tabular}{lll}
\hline Patterns & $\mathbf{n}$ & $\mathbf{\%}$ \\
\hline Comminuted & 19 & 52.78 \\
Transverse & 7 & 19.44 \\
Oblique & 5 & 13.89 \\
Spiral & 3 & 8.33 \\
Segmental & 2 & 5.56 \\
\hline
\end{tabular}

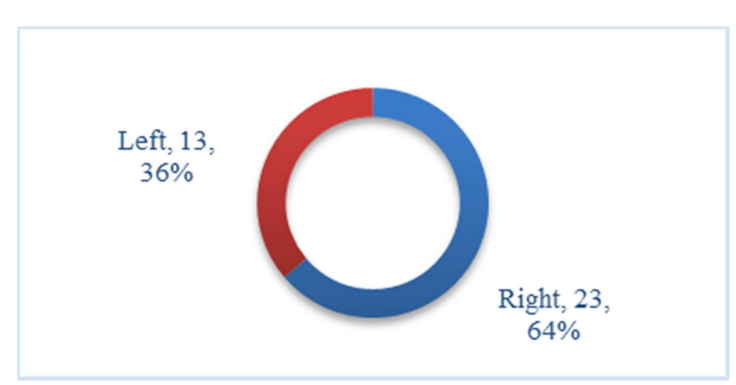

Figure 4. Distribution of sides of fractures $(n=36)$.

Table 3. Distribution of 'mode of injuries' of fractures $(n=36)$.

\begin{tabular}{lll}
\hline Mode of injury & $\mathbf{n}$ & $\mathbf{\%}$ \\
\hline RTA & 29 & 80.56 \\
Sports injury & 4 & 11.11 \\
Falls & 3 & 8.33 \\
\hline
\end{tabular}

Table 4. Karlstrom and Olerud criteria level $(n=36)$.

\begin{tabular}{lll}
\hline Satisfaction level & n & \% \\
\hline Excellent & 25 & 69.44 \\
Good & 8 & 22.22 \\
Fair & 2 & 5.56 \\
Poor & 1 & 2.78 \\
\hline
\end{tabular}

\section{Discussion}

There are many methods for stabilizing open tibial fractures. The problems are attributable mainly to the injury of skin, soft tissues and severity of the bone damage. In this study, the age of the patients ranged from 18 years to and more with the mean age of $31 \pm 4$ years. In our study, there were $69 \%$ males and $31 \%$ female participants. The sex incidence was similar to that of Tucker [13] where number of males was $23(88.5 \%)$ and that of females were $3(11.5 \%)$. Shtarker $\mathrm{H}$ et $\mathrm{al}^{14}$ also reported male preponderance over female in their study. In our Study we found $64 \%$ had fractures in the middle third, $22 \%$ in the proximal third and $14 \%$ in the distal third. This finding is similar to that of Shtarker et $\mathrm{al}^{14}$ who reported $81.3 \%$ middle third, $15.7 \%$ proximal third and 3.1\% lower third. In our study of 36 cases, there were $52.78 \%$ comminuted, $19.44 \%$ transverse, $13.89 \%$ oblique, $8.33 \%$ spiral and $5.56 \%$ segmental. This finding is near about similar to the finding of Shtarker et $\mathrm{al}^{14}$ who found 20 cases $(62.5 \%)$ in regard to comminuted fractures. In our study out of 36 participants, there were 11 (33\%) open type I, $56 \%$ open type II and $11 \%$ open type III A which is comparable with that of Shtarker et al. [14] The period between admission and Ilizarov ring fixation varied from 2 to 12 days with the average of 7 days in generally. It is generally agreed that ilizarov ring should be applied as soon as the general physical condition allowed. However, in this study Ilizarov ring fixation had to be delayed from 2 to 12 days from the date of injury because of insufficient operating days and facilities for emergency Ilizarov ring fixation. The average operating time varied from 90 minutes to 120 minutes. The finding was slightly lesser than that of Tucker [13] who reported that the operating time varied from 120 minutes to 210 minutes, though later it was reduced from 1 to 1.5 hours. The partial weight bearing on crutches was started on the very next day or on the $3^{\text {rd }}$ day and full weight bearing after 2 to 3 weeks. This is comparable to that of Dagher and Ronkoz [9] who reported that partial weight bearing was begum within $1^{\text {st }}$ week of operation and full weight bearing after 2 to 3 weeks. When using a uniplanar external fixator, Court-Brown et al [10] postponed weight bearing until the fixator was removed. In our study, the patients were discharged from the hospital on an average on the $5^{\text {th }}$ postoperative day. The average duration of hospital stay in this intervention was 12 days. Split thickness skin grafting was done in 5 cases in those who failed to heal spontaneously. In this study, the Ilizarov external fixator was removed after an average of 17 weeks (ranging from 12 to 22 weeks) which is in line with that of Shtarker et al [14] removed on an average of 16 weeks (ranging from 11-21 weeks). In our series, the average time of clinic-radiological union was 24.5 weeks (ranging from 21 to 28 weeks). The average time of union was 21 weeks for type I open fractures, 25.5 weeks for type II open fractures and 25 weeks for type IIIA open fractures. Tucker [13] reported the range of time to union as 12 to 47 weeks, with an average of 24.5 weeks. Shtarker et al [14] reported that the time to union was 21.5 weeks (ranging from 17.5 to 25.5 weeks). Keating [15] reported that the average time to union in reamed and unreamed locking intramedullary nailing in a series was 28 and 21 weeks for type I open fractures, respectively; 28 and 27 weeks for type II open fractures; 34 and 31 weeks for type IIIA open 
fractures. Weight bearing, to some degree, stimulates bone healing. Hulth[16] reported that the current concept of fracture healing was based on two variables namely blood supply and stability. In the present study, there were $22.22 \%$ of pin tract infection, manifested by pain, erythema and purulent discharge around the pin sites which was controlled by oral antibiotic within 10 days. There was no case of deep infection in this study. Tuker[13] reported approximately $10 \%$ of pin tract infection. According to the Karlstrom and Olerud criteria the highest $69.44 \%$ patient got 'excellent' result. Then $22.22 \%, 5.56 \%$ and $2.78 \%$ patients got 'good', 'fair' and 'poor' result respectively. The aim of this study was to evaluate the Ilizarov Technique in treating open fractures of tibia. In this study, according to the Karlstrom and Olerud criteria the highest $69.44 \%$ patient got 'excellent' result. Then $22.22 \%, 5.56 \%$ and $2.78 \%$ patients got 'good', 'fair' and 'poor' result respectively. The results of this current study may be considered as satisfactory.

\section{Conclusion and Recommendations}

In our study we found some good features of using Ilizarov induced method in the treatment of open fracture of lower one third of tibia. But to bring out more potential findings we would like to recommend for conducting more studies in several places in similar arena of the treatment procedure. Basically this was a single centered study with a small sized sample. So these findings may not reflect the exact scenario of the whole country.

\section{References}

[1] Court-Brown CM, McBirnie J. The epidemiology of tibial fractures. J Bone Joint Surg Br. 1995; 77: 417-21.

[2] Tornetta P, Bergman M, Watnik N, Berkowitz G, Steuer J. Treatment of grade-IIIb open tibial fractures. A prospective randomized comparison of external fixation and non-reamed locked nailing. J Bone Joint Surg Br. 1994; 76: 13-9.

[3] Hutchinson AJP, Frampton AE, Bhattacharya R. Operative fixation for complex tibial fractures. Ann R Coll Surg Engl. 2012; 94:34-8.

[4] Gustilo RB, Anderson JT. Prevention of infection in the treatment of one thousand and twenty-five open fractures of long bones: retrospective and prospective analyses. J Bone Joint Surg Am. 1976; 58: 453-8.
[5] Wani N, Baba A, Kangoo K, Mir M. Role of early Ilizarov ring fixator in the definitive management of type II, IIIA and IIIB open tibial shaft frac- tures. Int Orthop 2011; 35:915-23. [20445978] [http://dx.doi.org/10.100 7/s00264-010-1023-7]

[6] Hasankhani E, Payvandi MT, Bir- jandinejad A. The Ilizarov ring ex- ternal fixator in complex open frac- tures of the tibia. Eur J Trauma 2006; 32:63-8. [http://dx.doi.org/10. 1007/s00068-005-0031-6]

[7] Papaioannou N, Mastrokalos D, Papagelopoulos PJ, Tyllianaksi M, Athanassopoulos J, Nikiforidis PA. Nonunion after primary treatment of the tibia fractures with external fixa- tor. Eur J Orthop Surg Traumatol 2001; 11:231-35. [http://dx.doi.org/1 0.1007/BF01686895]

[8] Gustilo RB. Management of open fractures, in Gustilo RB (Ed.). Orthopaedic Infection, diagnosis and treatment, $1^{\text {st }}$ edition (Philadelphia:WB Saunders Company, 1989) 87-89.

[9] Paul, H Kim; Seth, S Leopold (9 May 2012). "GustiloAnderson Classification". Clinical Orthopaedics and Related Research. 470 (11): 3270-3274. doi:10.1007/s11999-0122376-6. PMC 3462875. PMID 22569719.

[10] "Ovid: Externer Link". Ovidsp.tx.ovid.com. Retrieved 201711-10.

[11] Trafton PG. Tibial shaft fractures, in Browner BD, Jupiter JB, Levine AM, Krettek C (Eds.). Skeletal trauma: basic science, management and reconstruction, 4th edition, Vol. 2 (Philadelphia: Saunders, 1998) 2319-2451.

[12] Golyakhovsky V, Frankel VH. Operative manual of Ilizarov techniques, (New Delhi: Jaypee Brothers, 1986).

[13] Tucker HL, Kendra JC, KInnebrew TE. Management of unstable open and closed tibial fractures using Ilizarov method, Clinical Orthopaedics and Related Research, 280, 1992, 125135 .

[14] Shtarker H David R, Stolero J, Grimberg B, Soundry M. Treatment of open tibial fractures with primary suture and Ilizarov fixation, Clinical Orthopaedics an Related Research, $335,1997,268-274$.

[15] Keating JF, Obrier PF, Blachut PA, Meck RN, Broekhuse HM. Locking intramedullary nailing with and without reaming for open fracture of the tibial shaft, The Journal of Bone and Joint Surgery, 79 A, 1987, 334-341.

[16] Hulth A. Basic science and pathology, current concept of fracture healing: Clinical Orthopaedics and Related Research, 249, 1989, 265-285. 